
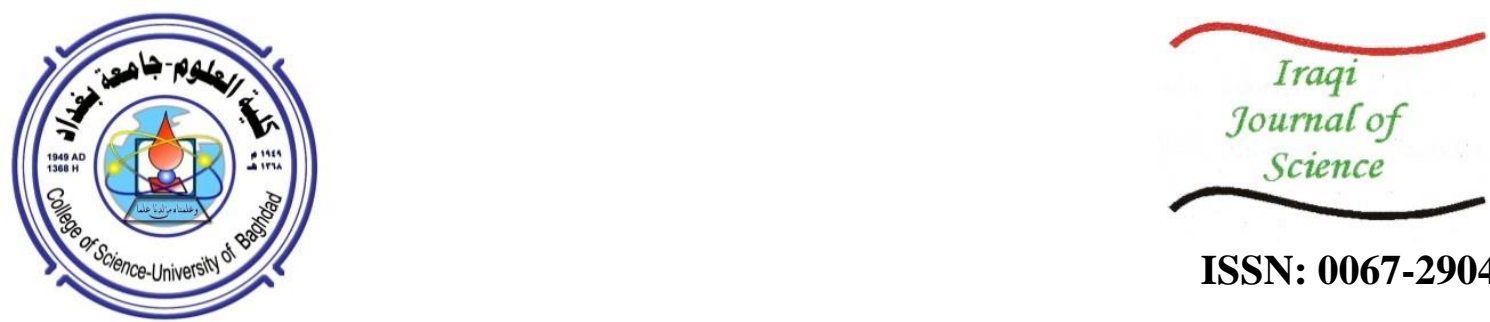

ISSN: 0067-2904

\title{
Petrophysical Properties and Digenetic Evolution of Shuaiba Formation in Nasiriyah Oil Field, Southern Iraq
}

\author{
Marwah H. Khudhair \\ Al-Karkh University of Science, Baghdad, Iraq \\ Received: 4/5/2021 \\ Accepted: 11/6/2021
}

\begin{abstract}
Shuaiba Formation is a carbonate succession deposited within Aptian Sequences. This research deals with the petrophysical and reservoir characterizations characteristics of the interval of interest in five wells of the Nasiriyah oil field. The petrophysical properties were determined by using different types of well logs, such as electric logs (LLS, LLD, MFSL), porosity logs (neutron, density, sonic), as well as gamma ray log. The studied sequence was mostly affected by dolomitization, which changed the lithology of the formation to dolostone and enhanced the secondary porosity that replaced the primary porosity. Depending on gamma ray log response and the shale volume, the formation is classified into three zones. These zones are A, B, and C, each can be split into three rock intervals in respect to the bulk porosity measurements. The resulted porosity intervals are: (I) High to medium effective porosity, (II) High to medium inactive porosity, and (III) Low or nonporosity intervals. In relevance to porosity, resistivity, and water saturation points of view, there are two main reservoir horizon intervals within Shuaiba Formation. Both horizons appear in the middle part of the formation, being located within the wells Ns-1, 2, and 3. These intervals are attributed to high to medium effective porosity, low shale content, and high values of the deep resistivity logs. The second horizon appears clearly in Ns-2 well only.
\end{abstract}

Keywords: Aptian Sequence, Petrophysical Properties, and Reservoir development, Nasiriyah Oilfield.

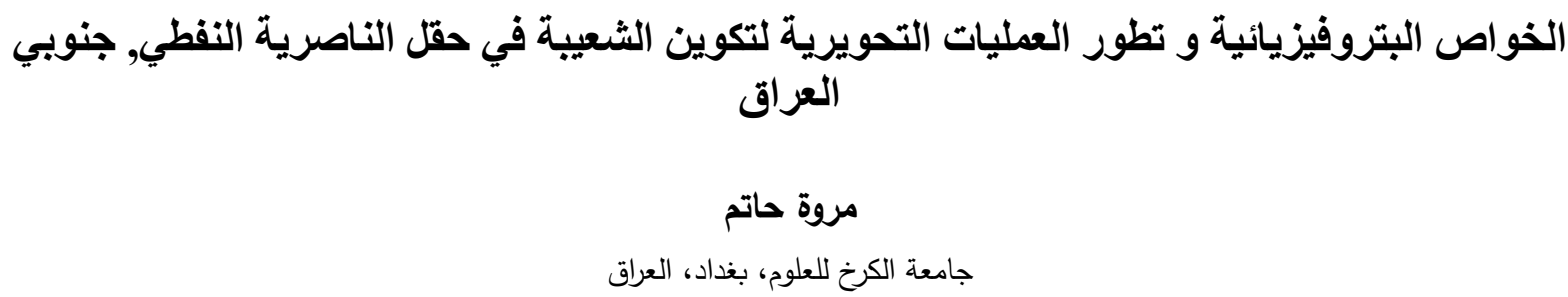

الخلاصة

ان التتابع المدروس يتمثل بتكوين شعيبة المترسب خلال دورة الابتيان. تضمنت الدراسة الحالية

بتروغرافية و الخواص المكمنية لخمسة ابار ضمن حقل الناصرية النفطي. تم تحديد الخواص البتروفيزيائية

باستخدام مختلف انواع المجسات كالمجسات الكهربائية (المجس الضحل و المجس العميق و مجس كعكة

الطين) و مجسات المسامية ( مجس النيترون و مجس الكثافة و المجس الصوتي) بالاضافة الى مجس اشعة

كاما. التتابع المدروس تاثر غالباً بالدلمتة التي حولت صخارية التكوين الى صخور الدولومايت مما ادى الى لى

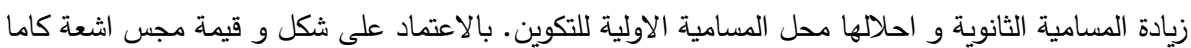

*Email: marwah_hatem@kus.edu.iq 


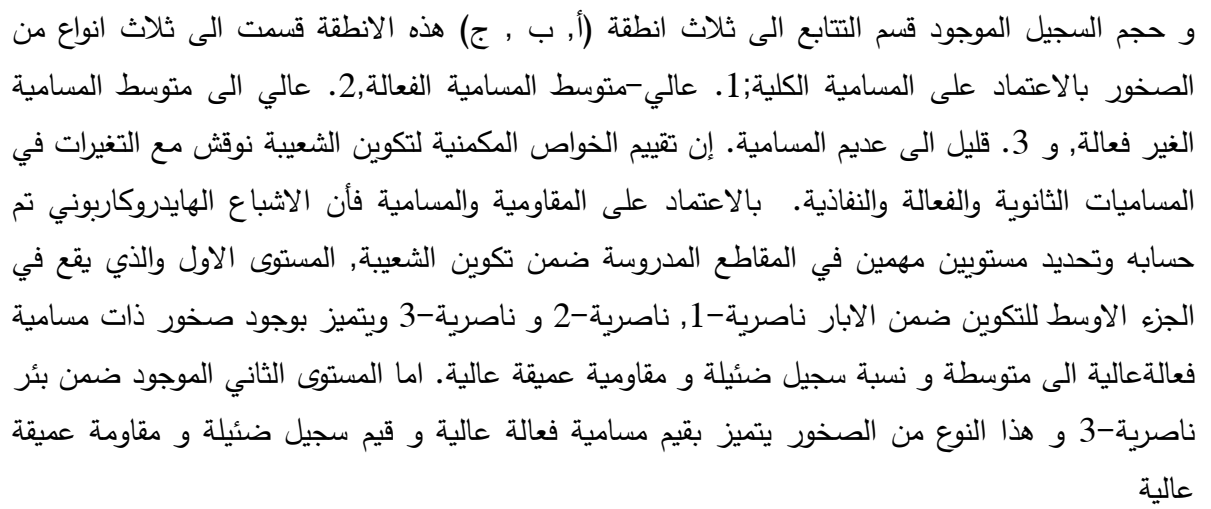

\section{1- Introduction}

The Shuaiba Formation represents a carbonate succession deposited during the Aptian cycle. This study includes petrophysical and reservoir characterizations for this succession in five boreholes within the Nasiriyah oilfield, sited in Nasiriyah Governorate, southern Iraq [1]. This field is an anticline within the Euphrates subzone that belongs to the Mesopotamian Zone with NW-SE direction axis [2] (Figure 1).

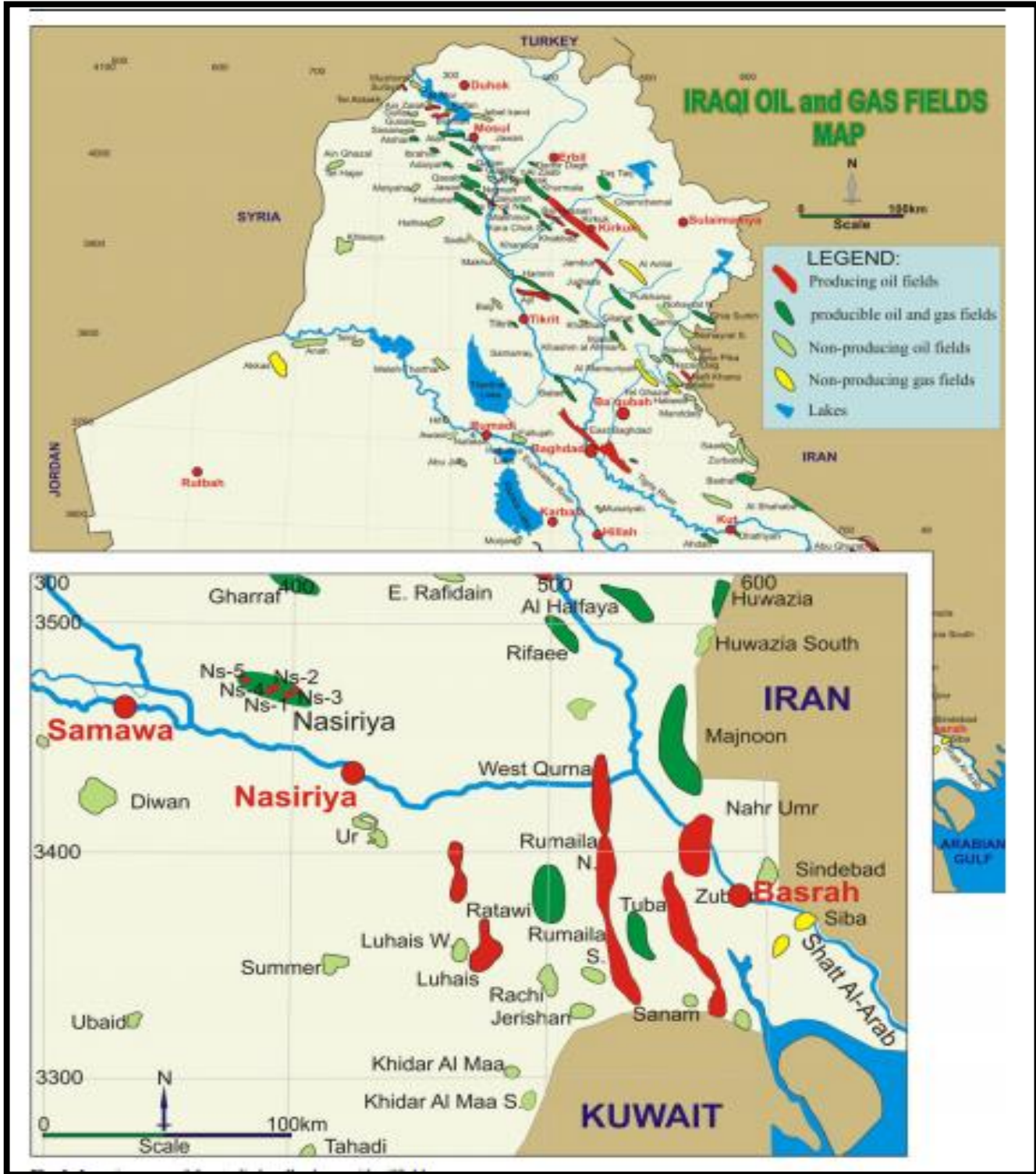

Figure 1-Location map of Nasiriya oil field with location of the five studied wells [3] 
Shuaiba Formation was primarily defined by Owen and Nasr in 1958 at well Zb-3, southern Iraq [4]. Shuaiba Formation is composed of 62 meters of oolitic (or pseudo-oolitic) limestone with fine-grained, organic, detrital, and sandy limestone. This interval changes gradually into chalky limestone and/or limestone with shale streaks in the uppermost part of this interval. Shuaiba Formation overlies Zubair Formation with a conformable and gradational contact. Zubair Formation passes laterally into Shuaiba Formation due to the fact that the former represents the shallow deltaic sediments, while the later represents the juxta-positioned relatively deeper marine environments [4]. The upper contact of the Shuaiba Formation is supposed to be a six million years old unconformity located in Kuwait [5]. [2] mentioned that Shuaiba Formation (age is from Hauterivion till Alpian time space) is represented by massive, rather argillaceouse, dolomitized limestone with some quartz silt interbedded with crystalline dolostone.

Ebraheem (2015) studied Reservoir properties at West Qurna oil field for Nahr Umr and Shuaiba formations. Depending on gamma ray results and the shale values, the formation was divided into three zones (A, B, and C). There are two types of reservoires based on the relationship between resistivity-porosity and hydrocarbon saturation; Type A appeared in the sand part of Nahr Umr Formation. Type B reservoir zone occurred in the top and bottom parts of Shuaiba Formation and has high to medium values of effective porosity with relatively high values of Latero Log Deep (LLD) [6].

The current study aims to determine the petrophysical characteristics of the Shuaiba Formation and the diagenetic development and effects on the reservoir properties. The reservoir model of the Shuaiba formation was constructed to conclude the best reservoir intervals.

\section{2- Methodology}

The present study was first conducted by digitizing the well logs (gama ray, density, neoutron, sonic, latero log deep, and latero log shallow) using the Didger software. The effect of invasion increase as the invasion diameter and resistivity contrast increase. The adjustments for well logs of Nasiriyah field must be made to log measurements to bring them back to the standard conditions for which the tool has been characterized. Different measurements require different corrections. The correction and interpretation of well logs were achieved by the interactive petrophysics software (IP) v3.5. It was found that differences between the original and the corrected log readings were slight and, thus, negligible. However, differences between the original and corrected recordings of the gamma ray, density, sonic, and resistivity logs were small. All data were corrected for environmental effects. Density logs were corrected for hole size and mud weight. Neutron logs was corrected for hole size, temperature, pressure, mud weight, and borehole salinity. Resistivity logs were corrected for borehole effects and mud filtrate invasion to derive the true formation resistivity and flushed zone resistivity. By using corrected data, the approaches of mineralogy identification, lithology, and logs interpretation were utilized by using the IP V3.5 software. Then, the petrophysical properties were determined and the petrophysical model was built throughout well correlations among Shuaiba successions.

\section{3- Results and Disscussion}

The interpretation of data is made through the direct reading of well logs as well as through established relationships and cross-plots in order to find the important lithological and petrophysical properties.

\section{3-1 Determination of shale volume}

Shale was almost containing the higher values of radioactivity than the other rock packages. Therefore, gamma-ray $\operatorname{logs}$ are usually used to indicate shale volume (V shale) in the successions. According to Larionov (1969), the gamma-ray index (IGR) was calculated primarily to calculate the $\mathrm{V}$ shale from the mentioned log.

Based on the $\mathrm{V}$ shale values, as well as the gamma-ray response, Shuaiba Formation was 
divided into three zones that are named as A, B, and C (Figure 2).

\section{Zone A}

This zone is considered as having relatively high values of shale content, which ranged 30-40 $\%$, with high gamma ray values. Generally, gamma ray log relatively refers to upward increasing of shale values. This zone appears at the upper part of Shuaiba Formation.

\section{Zone $B$}

This zone represents very low volume of shale (less than 10\%). This zone appears at the middle part of Shuaiba Formation.

\section{Zone $C$}

Zone $\mathrm{C}$ is the irregular log shape in all studied wells, with low shale value (10-20\%) in all studied wells. This zone appears at the lower part of Shuaiba Formation.

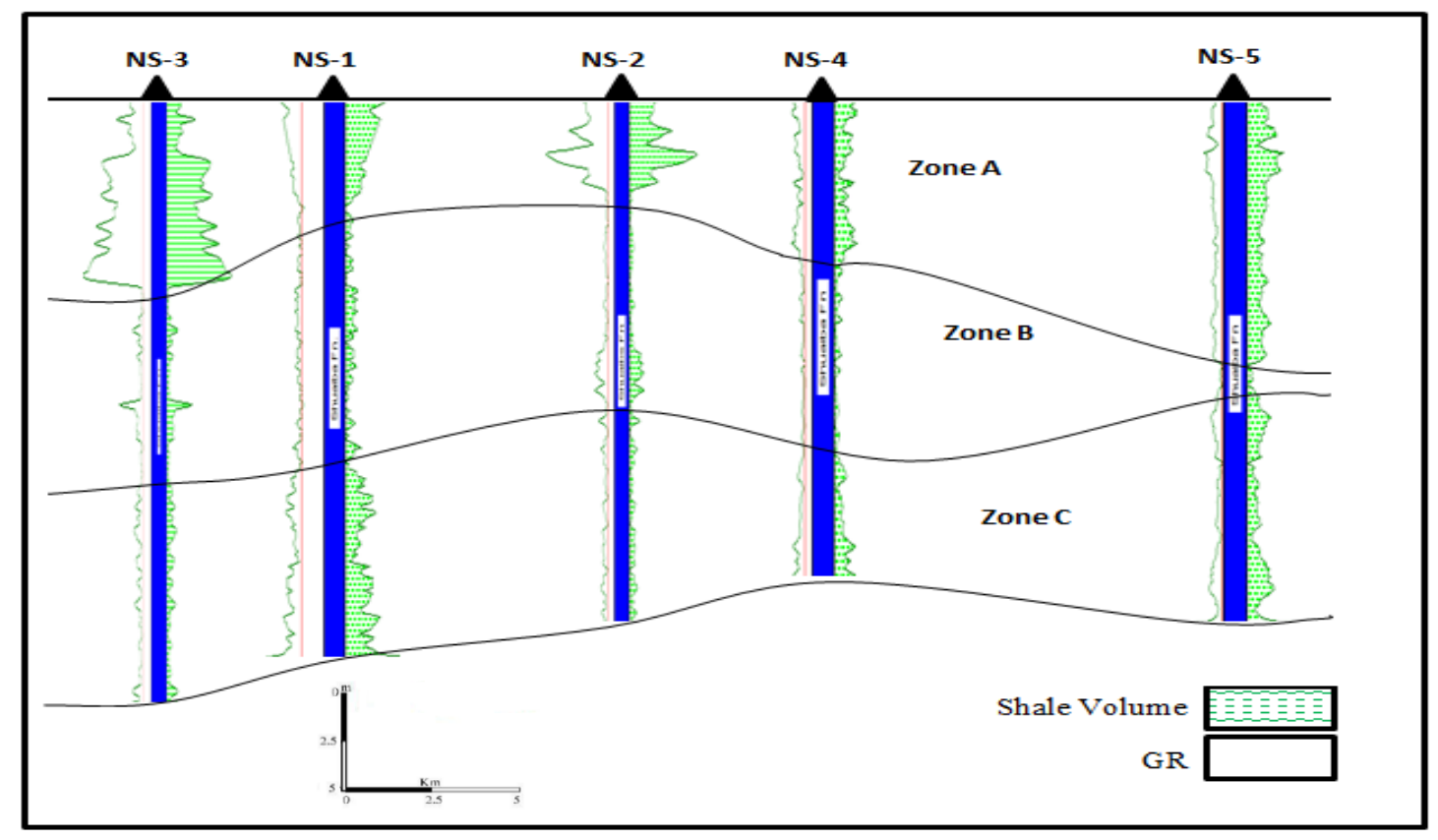

Figure 2-Lateral variation in gamma ray and volume of shale in the studied section within Nasiriyah oil field showing three zones (A, B, and C).

\section{3-2 Lithological Identification of Shuaiba Formation}

Lithology is a term used to describe the solid matrix portion of the rock, generally in the context of a description of the primary mineralogy of the rock [7].

Lithology identification of Shuaiba Formation was inferred from log responses using standard petrophysical cross plots. The lithology of Shuaiba succession was determined using two types of cross plots, as described below

\section{3-2-1 Density-Neutron Cross Plot for lithology identification}

The density-neutron cross plot is more important and traditional in lithology interpretation intersection. Thus, it is used to define the petrography of any formation. It is still frequently used to indicate the matrix and estimate the porous intervals within the formation in gasbearing formations. The basic plot takes the advantage of the differences between matrix densities of the main three rock types [8].

This cross plot is important in providing a satisfactory resolution of quartz, calcite, and dolomite minerals. In addition, this plot can be used to analyze the most common evaporate minerals that are easily identified [9]. Density-neutron cross plot of Shuaiba Formation shows points that are occurring in the dolomite field, with small ones found in the limestone and shale fields. This implies that the main lithology of Shuaiba Formation is dolostone, as illustrated in Figure 3. 


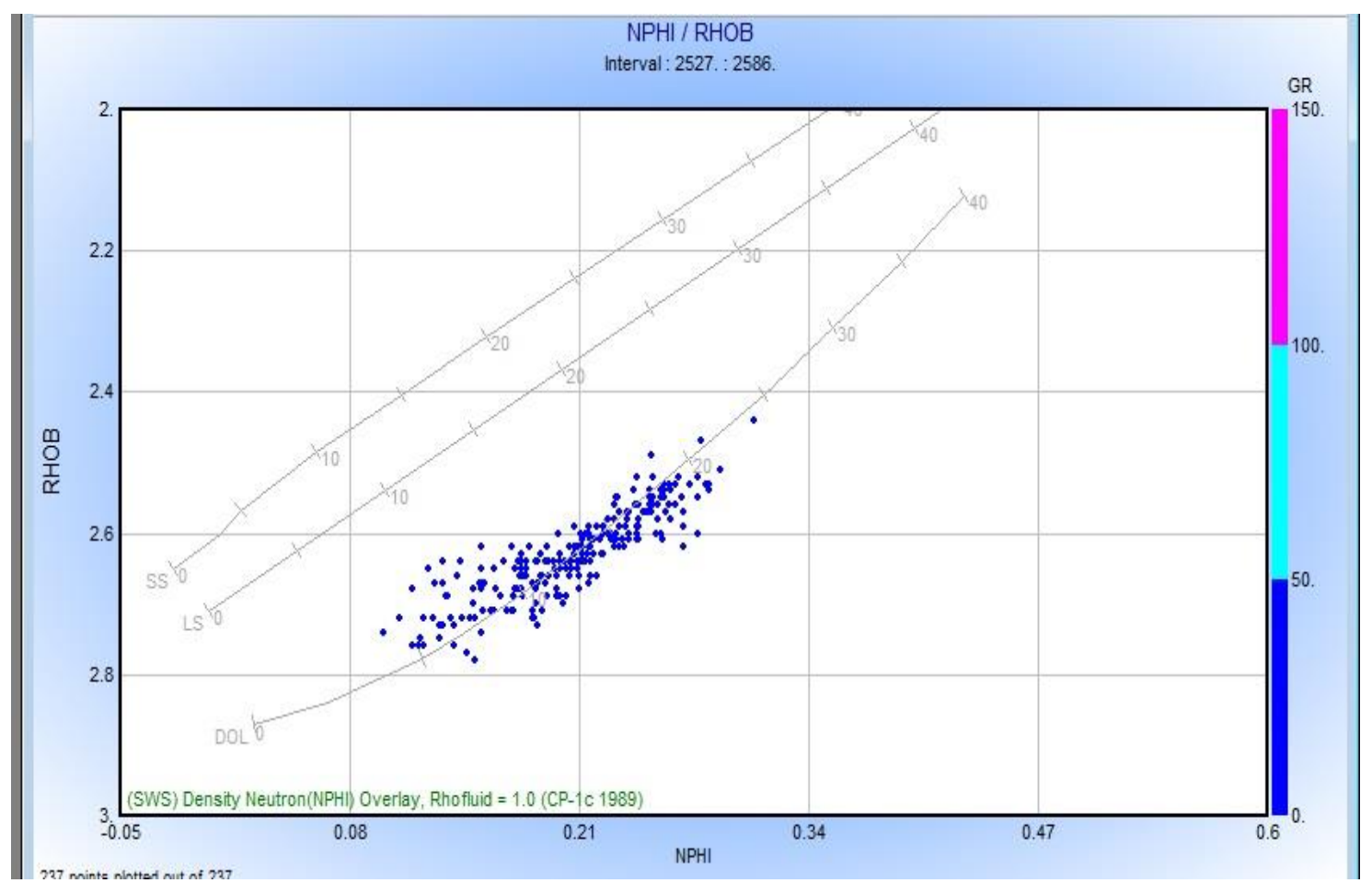

Figure 3-Neutron-density cross plot for Shuaiba formation in well Ns-1

\section{3-2-2 M-N Cross-Plot identifications}

Schlumberger [6] presented the demonstration procedure of this type of cross plots for mineral identification. It is a two-dimensional display of all three porosity log responses in complex reservoir rocks [10].

The M-N cross plot for Shuaiba Formation is a good indicator of secondary porosity, as illustrated in Figure 4. Moreover, few numbers of points occurred in the shale region in all studied wells. These results show that the data are centered on the dolomite area, with an extension toward the secondary porosity area, with a little shale. Thus, it can be decided that most of the formation consists of dolomite, as represented by the dolomite region, with some anhydrite represented by the points of anhydrite region.

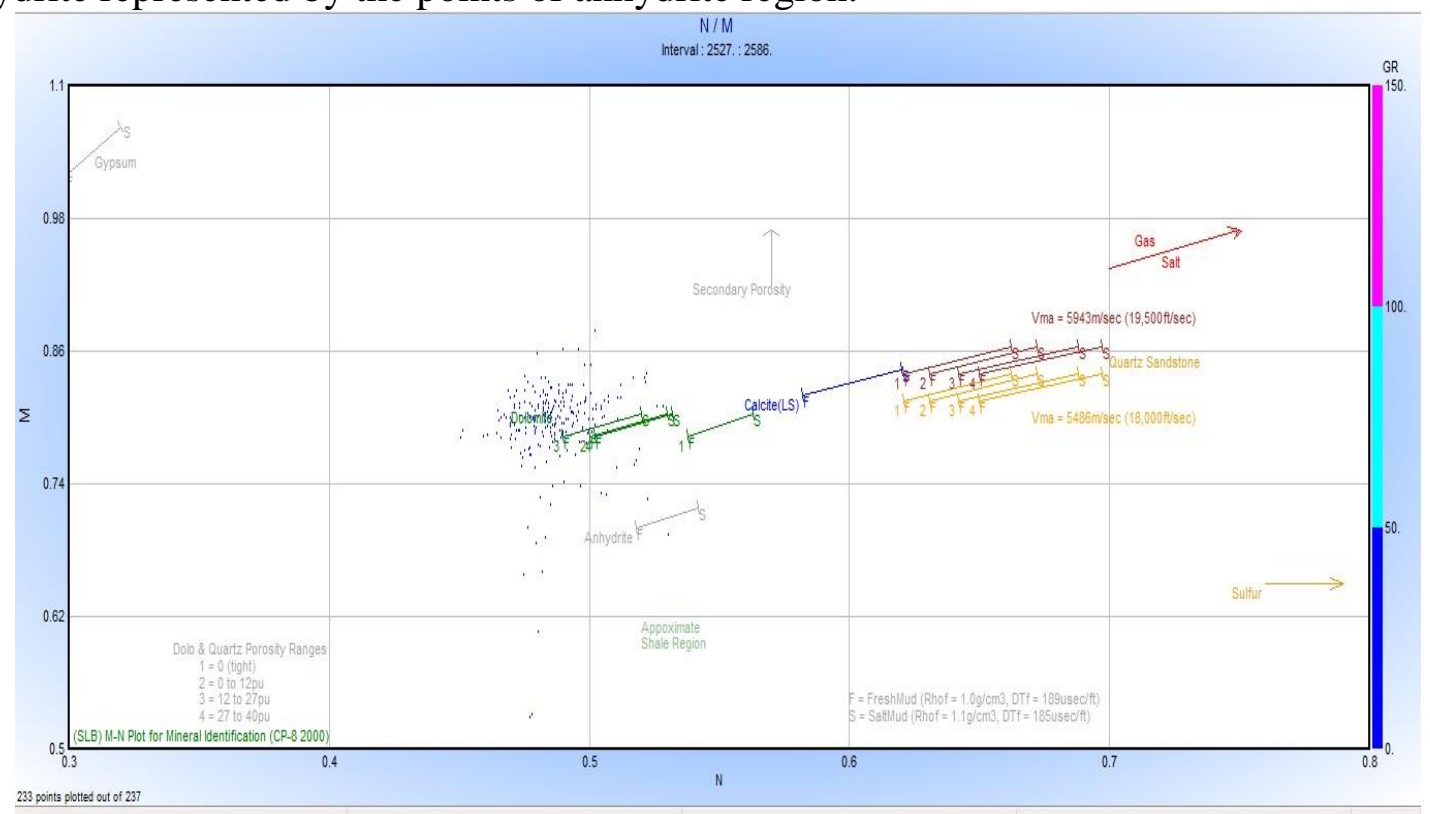

Figure 4-The M-N cross plot for Shuaiba Formation in the well Ns-1. 
As a result, lithology (N-D) and mineral (M-N) cross-plots indicated that the main lithology for Shuaiba is dolomite with some shale.

\section{3-3 Evaluation of sequence porosity}

Based on gamma ray and V shale values, Shuaiba succession is divided into three main zones (A, B, and C.); therefore, we have an interpretation of the logs porosity and porosity evaluation according to these divisions. The correlation of the porosity logs among the studied boreholes showed an approximate matching with these zones.

\section{Zone A}

According to the total porosity, two rock units, high-medium inactive porosity rocks (type II), and low-non pore rocks (type III) were characterize in zone A. The type II appeared in all studied wells, representing the shale rich rocks. This unit has poor permeability (inactive porosity). The type (III) represents the non-porous rock units, that are presented in all studied wells, as a thin layer (Figure 5).

\section{Zone B}

The zone B is comprised by tow horizons; the first has high to medium effective porosity (type I), while the second is characterized by non-porous rocks (type III) (Figure 5).

\section{Zone $C$}

The zone $\mathrm{C}$ is characterized by high to medium effective porosity (type I) and high to medium inactive porosity (type II). This zone occurred in all studied wells (Figure 5).

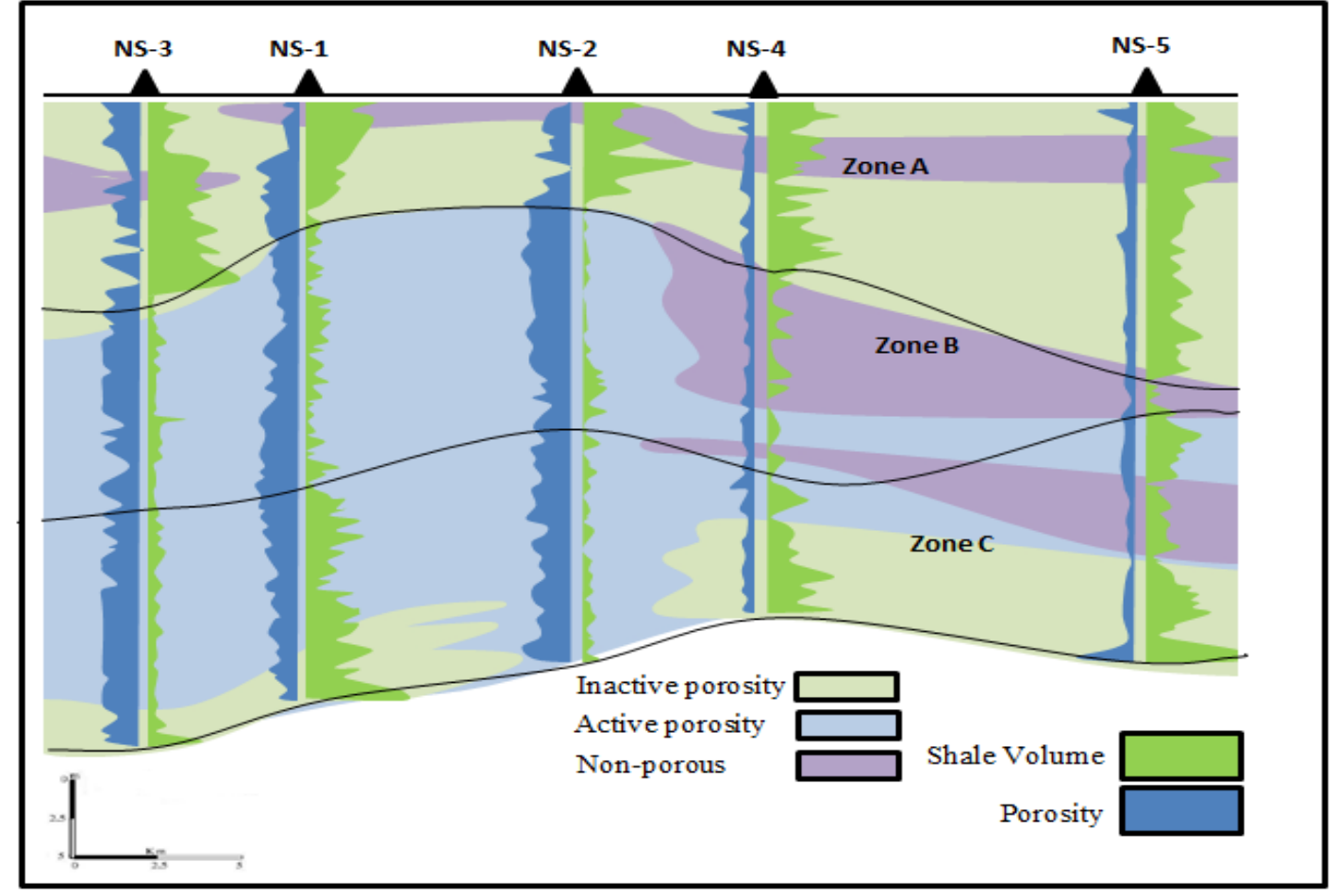

Figure 5-porosity value in the studied section within Nasiriyah oil field showing porosity variation.

\section{3-4 Water and hydrocarbon saturation}

The saturation of the fluid is usually obtained from the resistivity logs. Various resistivity values were recorded with multiple fluid saturations that occurred at different intervals from the borehole. The water saturation value is indicated from the resistivity logs by using the Archi equation. This equation acquires the information from resistivity tools, porosity suit, water saturation, and formation's water resistivity [11].

According to the relationship between resistivity-porosity and the saturation of hydrocarbons, there are two horizons of reservoir (hydrocarbon apperance) within Shuaiba Formatin: 


\section{Horizon 1 (within zone B)}

This horizon appears in the middle part of Shuaiba Formation within NS-1, 2, and 3 wells (Figure-1). This type of rock units is characterized by high to medium effective porosity, with low V shale and high values of deep resistivity values (Rt), as illustrated in Figure 6.

\section{Horizon 2 (within zone C)}

This Horizon appeares within Ns-2. This interval is characterized by high to medium effective porosity, with low V shale and high Rt (Figure 6).

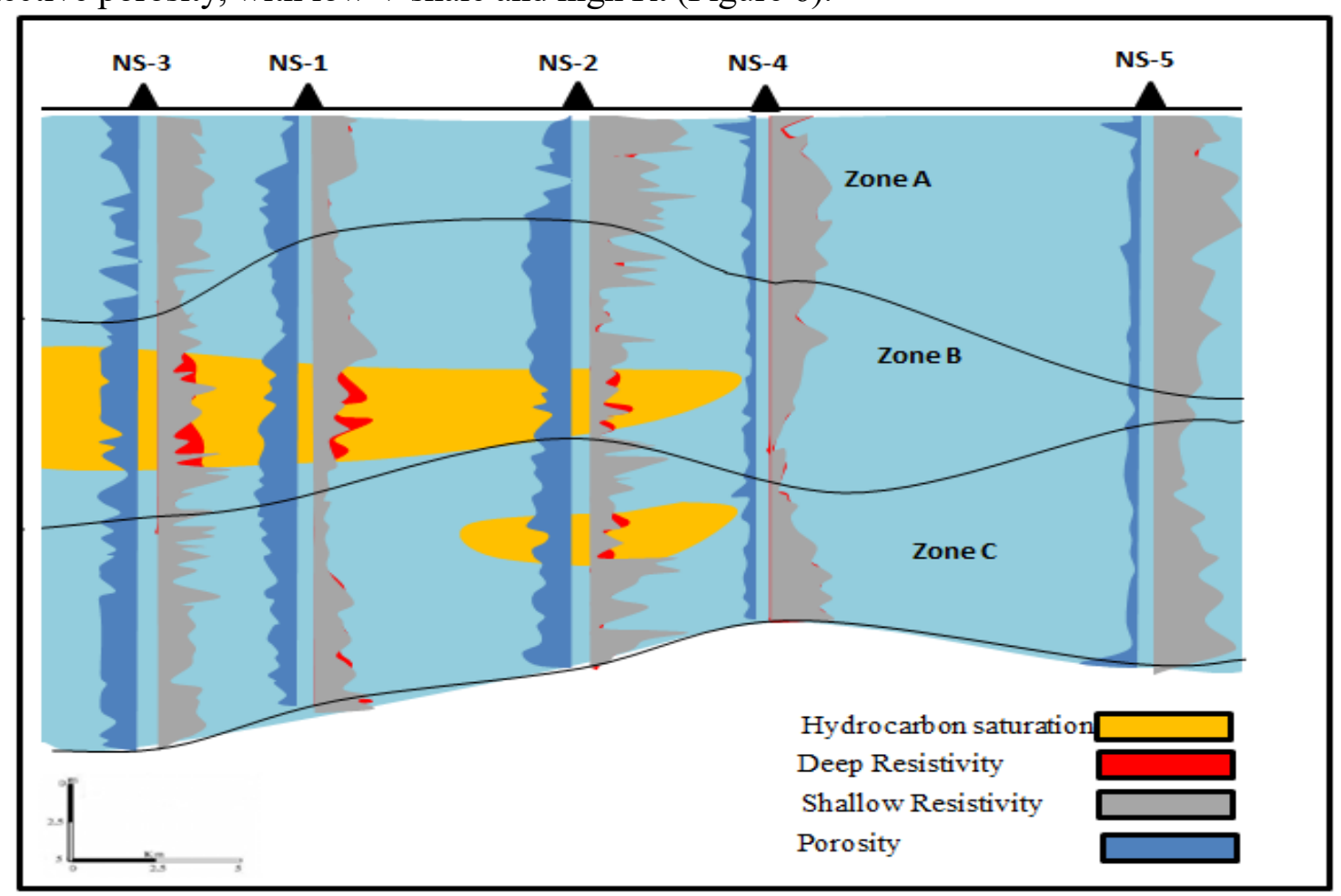

Figure 6-Hydrocarbon saturation in the study wells.

\section{3-5 Bulk Volume Analysis}

Figure 7 presents Computer Processed Interpretation (C.P.I) results for well Ns-1, which is depicted as in the followings: Porosity analysis track that is divided into effective porosity $(\varphi \mathrm{e})$, porosity filled with water in the invaded zone (Bvwsxo), and porosity filled with water in the uninvaded zone (Bvw). The interval between Bvwsxo and Bvw comprises the movable hydrocarbon, while the interval that separates $\varphi=$ and Bvw indicates total hydrocarbon. Bulk volume analysis is represented by the effective porosity ( $\varphi$ e), shale percentage (Vsh), and non-shale matrix percentage (Vmatrix). 


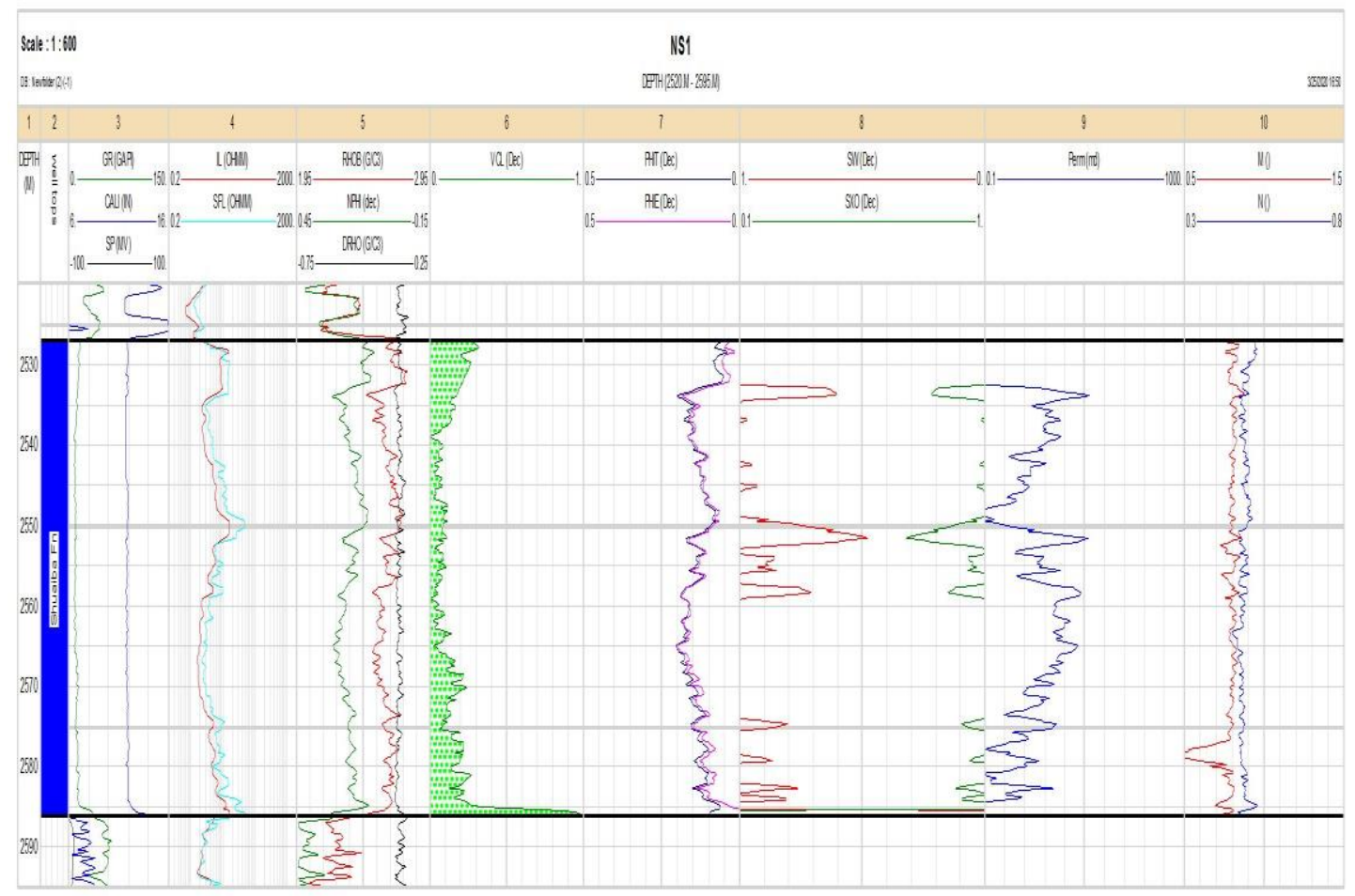

Figure 7- Fluid and formation analysis of the well Ns-1.

\section{4- Discussion and conclusions}

Shuaiba Formation can be divided by gamma rays and shale value into three zones (A, B and C). We conducted an interpretation of porosity records and an assessment of porosity according to these regions. The porosity records show that the studied wells have an approximate match with those zones divided by gamma rays and shale value.

Total porosity, effective porosity, and secondary porosity were calculated from neutron, density, and sonic logs, showing that the secondary porosity is dominant and primary porosity is too little or ignored.

Lithology (N-D) and mineral (M-N) cross-plots indicated that the main lithology for Shuaiba is dolomite with some shale.

These areas are divided into three types of rocks according to total porosity; moderately high active porous rocks (type I), moderately high inactive porous rocks (type II), and low nonporous rocks (type III).

Zone A contains two types of rocks according to their total porosity; the inactive hightemperate porous rocks (type II) and the low-porous rocks (type III). Type II appears in all studied wells, and it is represented in rocks rich in shale. This unit has a weak permeability (inactive porosity). Type III represents the non-porous rocks that appeared in all studied wells as a thin layer.

Zone $\mathrm{B}$ is characterized by tow horizons, one is characterized by high- medium active porosity (type I) while the second is non-porous (type III).

Zone $\mathrm{C}$ is represented by high-medium active porosity (type I) and high - medium inactive porosity (type II). This appeared in all studied wells.

According to the relationship between resistivity-porosity and hydrocarbon saturation, there are two horizons of reservoir (hydrocarbon apperance) within Shuaiba Formatin; Horizon 1 (within zone B) appears in the middle part of Shuaiba Formation within NS-1, NS-2, and NS-3 wells. This type of rocks is characterized by high-medium effective porosity with low volume of shale and high deep resistivity. Horizon 2 (within zone C) appears within Ns-2 well. This type of rocks 
is characterized by high-medium porosity (effective porosity) with low volume of shale and high deep resistivity $(\mathrm{Rt})$.

\section{References}

[1] K. M. AL- Naqib, "Geology of Arabian Peninsula, South western Iraq," US. Geol. Survey Prof. Paper, 560-G,p. 5, 1967.

[2] T. Buday and S. Z. Jassim, "The Regional Geology of Iraq," Vol.2: Tectonism, Magmatism and Metamorphism. Publication of GEOSURV, Baghdad, 352p, 1987.

[3] A. J. Al-Khafaji, "The Mishrif, Yamama, and Nahr Umr reservoirs petroleum system analysis, Nasiriya oilfield, Southern Iraq," Arab J Geosci. Vol. 8, Issue 2, pp. 781-798, 2015.

[4] R. C. Bellen, H. V. Dunnington, R. Wetzel, and D. Morton, "Lexique Stratigraphique", Interntional. Asie, Iraq, vol. 3c. 10a, 333p, 1959.

[5] S. Z. Jassim, and J. C. Goff, "Geology of Iraq," .Dolin, Prague and Moravian Museum, Brno. $341 \mathrm{p}, 2006$.

[6] N. J. Abid, S. S. Al-Shaikhly, A. A. H. Al-Zaidy, "Facies Architecture and Diagenetic Features Development of Albian-Early Turonian Succession in Luhais Oil field, Southern Iraq," Iraqi Journal of Science, vol 56, no.3B, pp: 2308-2320, 2015.

[7] G. Asquith, and C. Gibson, C., "Basic well log analysis for geologists: methods in Exploration series," AAPG, 216p, 1982.

[8] V.E. Darwin and J.M. Singer, "Well Logging for Earth Scientists," 2nd Edition. Springer + Business Media B.V., 2008.

[9] A. A. H. Al-Zaidy, Z. Amer, "Facies Analyses and Diagenetic features development of Albian Aptian Succession in the Wset Qurna oil field, Southern Iraq," Iraqi Journal of Science, vol. 56, no.4A, pp: 2887-2901, 2015.

[10] Schlumberger, "Log Interpretation Charts," 151p, 1989.

[11] G.E. Archie, "The electrical resistivity $\log$ as an aid in determining some reservoir characteristics," Trans AIME, vol.146, pp.54-62, 1942. 